Applications of Surface Science 6 (1980) 273-287

(c) North-Holland Publishing Company

\title{
AN INFRARED SPECTROSCOPIC STUDY OF THE ADSORPTION OF CARBON MONOXIDE ON SILICA-SUPPORTED COPPER PARTICLES
}

\author{
K.P. de JONG, J.W. GEUS and J. JOZIASSE \\ Department of Inorganic Chemistry, University of Utrecht, \\ 3522 AD Utrecht, The Netherlands
}

Received 13 May 1980

Revised manuscript received 28 July 1980

\begin{abstract}
Infrared spectroscopy is used to study the adsorption of carbon monoxide $\left(20^{\circ} \mathrm{C} ; 0.1-\right.$ 100 Torr) on copper-on-silica catalysts differently prepared and pretreated. As determined by electron microscopy and X-ray line broadening, the catalysts contain copper particles having sizes of 60 to $5000 \AA$ depending on the preparation procedure and the thermal treatment. Adsorbed carbon monoxide displays broad infrared absorption bands exhibiting a maximum at 2099 to $2146 \mathrm{~cm}^{-1}$. The position of the maximum varies with the preparation and pretreatment of the catalyst. With deposition-precipitated catalysts (Cu-particles 60-120 $\AA$ ) prolonged reduction at $300^{\circ} \mathrm{C}$ causes the maximum to shift from 2104 to $2139 \mathrm{~cm}^{-1}$. The shift is attributed to initial facetting and subsequent rounding of the small copper particles. An impregnated catalyst $(40-5000 \AA)$ shows a shift from 2146 to $2129 \mathrm{~cm}^{-1}$ upon more severe reduction, which is ascribed to sintering to large copper particles.
\end{abstract}

\section{Introduction}

The vibrational spectrum of adsorbed carbon monoxide is a sensitive means for investigating the atomic structure of metallic surfaces. Van Hardeveld and Hartog [1], e.g., demonstrated this with nickel-on-silica catalysts. They found that different sites on the nickel surface gave rise to different absorption bands in the infrared spectrum of adsorbed carbon monoxide. These bands could be resolved at room temperature.

The adsorption of carbon monoxide on metals with filled $d$ shells, such as copper, silver and gold, is much weaker than on metals which form bulk carbonyls. The binding is probably of an electrostatic nature, which can be understood in terms of quadrupole-quadrupole interaction between carbon monoxide and the metal. With this interaction the bond-strength depends on the coordination number of the copper atoms in the surface. Since the interaction is weak, differences in surface structure will not give rise to absorption bands displaying well resolved maxima, as with nickel. However, the extensive work of Pritchard [2] on copper single crystal surfaces has demonstrated that the surface structure of copper is at least correlated 
with the position of the peak maximum of the absorption band of adsorbed carbon monoxide.

The tendency for copper particles to be facetted is relatively small. Sundquist [3] concluded to a small anisotropy of surface energy from an investigation of the shape of copper particles of the order of $1 \mu \mathrm{m}$. Later McLean [4] established that the degree of anisotropy of surface energy for copper was less than $4 \%$. We therefore expect that small copper particles will have a large fraction of atomically rough areas in their surface. We wanted to investigate the relation between the surface structure of small copper particles and the vibrational frequency of adsorbed carbon monoxide more in detail. We feel that the experimentally easily accessible vibrational spectrum of adsorbed carbon monoxide can be a valuable tool for the characterization of the surface structure of copper catalysts.

Since we expect the particle size to affect the proportion of differently structured surfaces, we need copper catalysts of a particle-size distribution that is well known and as narrow as possible. As reduction must be performed at high temperatures for prolonged periods without too severe a loss of copper surface, an appreciable interaction between the metal and the carrier is, moreover, a prerequisite. Deposition-precipitation by means of hydrolysis of urea meets the above requirements. This method was used to prepare two copper catalysts of a different metal content. Another catalyst was prepared by the conventional procedure of impregnation and drying.

In the literature changes in the infrared absorption band of adsorbed carbon monoxide on copper catalysts have been attributed to incomplete reduction $[2,5]$. We wanted to discriminate between the influence of the surface structure of the metal particles on the one, and the degree of reduction on the other hand. We therefore varied the reduction temperature and time of the catalyst before admitting carbon monoxide. We, moreover, studied the interaction of carbon monoxide with oxygen adsorbed on copper. Adsorption of carbon monoxide was studied at room temperature in the pressure range 0.1 to 100 Torr.

$\mathrm{X}$-ray diffraction line broadening and transmission electron microscopy were used to characterize the catalysts.

\section{Experimental}

Catalysts CU-1 and CU-2 containing 16.7 and 30 wt.\% copper, respectively, were prepared by deposition-precipitation. In a suspension of silica (Aerosil $200 \mathrm{~V}$ ) in a cupric nitrate solution the hydroxide was homogeneously precipitated by decomposition of urea at $90^{\circ} \mathrm{C}$. X-ray diffraction line broadening yielded a value of $110 \AA$ for CU-1 and $190 \AA$ for CU- 2 for the diameter of the copper particles after reduction of the catalysts at $300^{\circ} \mathrm{C}$. Catalyst CU-3 was prepared by the conventional method of impregnating the carrier with a cupric nitrate solution and drying. This catalyst had a copper content of $10 \mathrm{wt} . \%$. 
After drying the samples were pressed into discs of approximately $0.1 \mathrm{~mm}$ thickness. A disc was placed into an all-glass cell with sodium chloride windows. The disc could be moved to a furnace section where the pretreatment could be carried out. Before reduction the catalysts were calcined in an oxygen flow at $400^{\circ} \mathrm{C}$ for $15 \mathrm{~h}$. Reduction times and temperatures $\left(200-400^{\circ} \mathrm{C}\right)$ were varied at a total pressure of $1 \mathrm{~atm}$. with a mixture of $10 \% \mathrm{H}_{2}$ and $90 \% \mathrm{Ar}$.

The cell had been permanently placed in the spectrophotometer and coupled to a vacuum apparatus. After reduction the cell was evacuated for $30 \mathrm{~min}$, with the catalyst at a temperature $25^{\circ} \mathrm{C}$ below the reduction temperature. Pressures as low as $10^{-7}$ Torr ( 1 Torr $=133.3 \mathrm{Nm}^{-2}$ ) could be maintained by means of an ion getter pump (Riber - $25 \ell \mathrm{s}^{-1}$ ).

Spectra were recorded at room temperature with a Perkin-Elmer $580 \mathrm{~B}$ infrared spectrophotometer. The absorbance of gaseous carbon monoxide was compensated for by means of an identical cell, placed in the reference beam of the spectrophotometer, and coupled to the measuring cell. It was checked that no adsorption of carbon monoxide appeared on the silica carrier under out experimental conditions.

Gaseous carbon monoxide (purity 99.997\%) was obtained from L'Air Liquide and used without further purification.

For transmission electron microscopic studies the catalysts were reduced at $300^{\circ} \mathrm{C}$ and suspended in methylmetacrylate, which was polymerized at $60^{\circ} \mathrm{C}$. Thin sections suitable for the electron microscope were cut with an ultra-microtome (Reichert). Two electron microscopes have been used i.e. a Philips EM 200 and a Jeol $200 \mathrm{C}$. The samples were studied both in bright and in dark field.

\section{Results}

\subsection{Infrared spectra}

With all copper particles studied, adsorbed $\mathrm{CO}$ showed broad infrared absorption bands at frequencies from 2040 to $2170 \mathrm{~cm}^{-1}$. Consequently, differently bonded $\mathrm{CO}$ was always present at our copper surfaces. For reduced samples the position of the peak maximum did not vary markedly with the $\mathrm{CO}$ pressure. Usually spectra were recorded at a $\mathrm{CO}$ pressure of 50 Torr.

With catalyst CU-1 (16.7 wt.\%) the influence of cyclic reduction-oxidation on the infrared absorption band of adsorbed $\mathrm{CO}$ was investigated. The reduction temperatures and times were varied with intermediate oxidation at $300^{\circ} \mathrm{C}$ in an oxygen flow of $1 \mathrm{~atm}$. The results have been summarized in fig. 1 and table 1 . The first three cycles shifted the band maximum from 2104 to $2139 \mathrm{~cm}^{-1}$. This shift to higher wavenumbers is very well reproducible, as is apparent from an experiment with a fresh disc performed with another vacuum apparatus and infrared spectrophotometer (Grubb Parsons). After reduction for $12 \mathrm{~h}$ at $300^{\circ} \mathrm{C}$ we found the peak at $2099 \mathrm{~cm}^{-1}$. Subsequent reduction for $17 \mathrm{~h}$ at the same temperature shifted the band maximum to $2131 \mathrm{~cm}^{-1}$. 


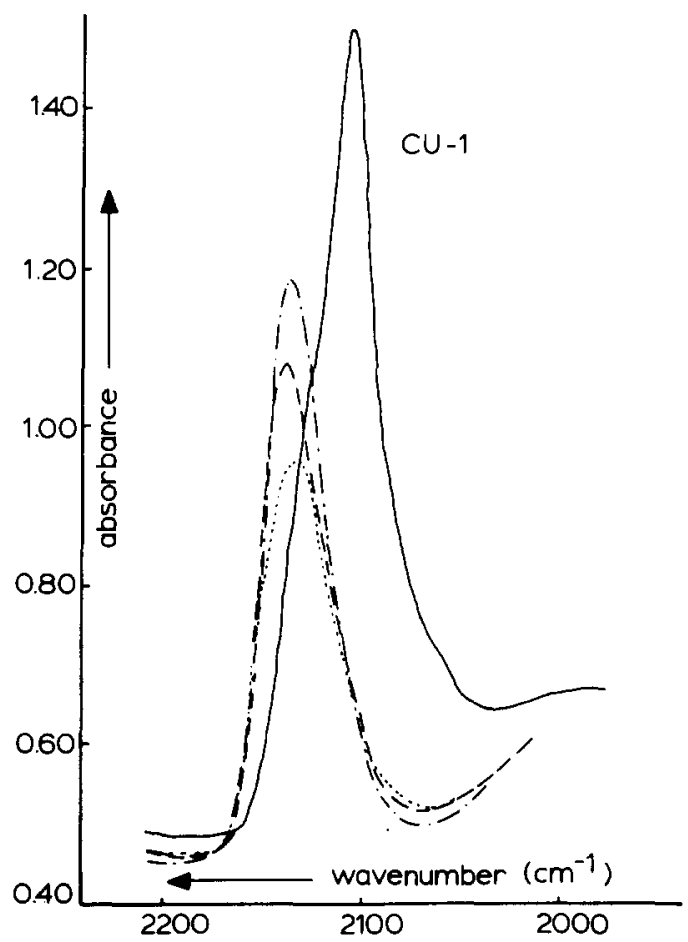

Fig. 1. Infrared spectra of $\mathrm{CO}$ adsorbed on $\mathrm{Cu} / \mathrm{SiO}_{2}$, sample $\mathrm{CU}-1$. After reduction number 1 $(-), 2(\ldots),. 3(---)$ and $7(-.-$.$) . See also table 1$.

Evacuation for $20 \mathrm{~min}$ at room temperature removed the adsorbed $\mathrm{CO}$ almost completely. The behaviour of the absorption band on evacuation did not vary markedly with the reduction-cycle number.

Table 1

Influence of cyclic reduction and reoxidation on the infrared absorption band of adsorbed $\mathrm{CO}$ for catalyst CU-1, CO pressure 50 Torr

\begin{tabular}{lllll}
\hline Reduction & $\begin{array}{l}\text { Temperature } \\
\left(\mathrm{C}^{\circ}\right)\end{array}$ & $\begin{array}{l}\text { Time } \\
(\text { hours })\end{array}$ & $\begin{array}{l}\text { Peak maximum } \\
\left(\mathrm{cm}^{-1}\right)\end{array}$ & Absorbance \\
\hline 1 & 300 & 15 & 2104 & 1.03 \\
2 & 300 & 2 & 2131 & 0.52 \\
3 & 300 & 15 & 2139 & 0.60 \\
4 & 300 & 2 & 2139 & 0.56 \\
5 & 300 & 15 & 2138 & 0.61 \\
6 & 400 & 15 & 2136 & 0.77 \\
7 & 400 & 15 & 2135 & 0.65 \\
\hline
\end{tabular}


Reduction of copper oxide was already complete after $2 \mathrm{~h}$ at $300^{\circ} \mathrm{C}$, as can be seen from the reductions 4 and 5 of table 1 . Variation of the reduction temperature in the range $300-400^{\circ} \mathrm{C}$ had only a small influence on the infrared absorption band (reduction 5 and 6 of table 1). Thermogravimetric experiments have also established the rapid complete reduction of the copper species of the catalysts at $300^{\circ} \mathrm{C}$. The shift of the band maximum is therefore not due to a different extent of reduction and thus a different content of not reduced copper ions.

The influence of oxygen on the infrared absorption band of adsorbed carbon monoxide was investigated with $\mathrm{CU}-1$ after reduction 3. After dosing of 50 Torr $\mathrm{CO}$ the peak frequency was $2139 \mathrm{~cm}^{-1}$ and the absorbance 0.60 (table 1). Admission of 50 Torr $\mathrm{O}_{2}$ shifted the band maximum to $2135 \mathrm{~cm}^{-1}$ and raised the absorbance to 1.20. On evacuation at room temperature the absorption band remained at a stable intensity of more than $40 \%$ of its original value. The different effect of evacuation at room temperature demonstrates that the interaction of $\mathrm{CO}$ is much stronger with an oxidized than with a reduced copper surface. The above results indicate that the stability of the absorption band against evacuation is a more reliable criterion for the degree of reduction of the surface than is the position of the band maximum.

Catalyst CU-2 was always reduced for $15 \mathrm{~h}$, but now the reduction temperature was varied. Because of the high metal content of the catalyst (about $30 \mathrm{wt} . \%$ ) the absorption bands were very strong and therefore difficult to measure accurately. The results have been summarized in fig. 2 . After reduction at $200^{\circ} \mathrm{C}$ the absorption band was centered around $2130 \pm 6 \mathrm{~cm}^{-1}$. Intermediate oxidation and reduction at $300^{\circ} \mathrm{C}$ led to a peak maximum at $2136 \pm 2 \mathrm{~cm}^{-1}$. Prolonged reduction at $300^{\circ} \mathrm{C}$ did no more affect the band position and intensity of the absorption band. From fig. 2 it is apparent that the first reoxidation and reduction shifted the maximum of the $\mathrm{CO}$ absorption band to higher wavenumbers, as with catalyst $\mathrm{CU}-1$. The shift of the maximum is, however, less pronounced than with CU-1.

Upon exposure to oxygen the band intensity of adsorbed $\mathrm{CO}$ increased, but the position did not change. As with CU-1 the adsorption on the oxidized surface was stronger.

The results for the impregnated catalyst CU. 3 have been summarized in fig. 3 and table 2. It can be seen that the effect of more severe reduction is the reverse of that displayed by the other catalysts. After the first reduction $\left(300^{\circ} \mathrm{C}\right)$ the peak maximum was situated at $2139 \mathrm{~cm}^{-1}$. Another fresh disc of this catalyst reduced for $30 \mathrm{~min}$ at $300^{\circ} \mathrm{C}$ even displayed the peak maximum at $2146 \mathrm{~cm}^{-1}$. Subsequent reduction at $400^{\circ} \mathrm{C}$ shifted the peak to $2129 \mathrm{~cm}^{-1}$ with a shoulder at $2100 \mathrm{~cm}^{-1}$.

Reduction 3 of CU-3 (table 2) was carried out at $200^{\circ} \mathrm{C}$ after intermediate oxidation of the catalyst. After the third reduction the sample showed the same absorption band as when reduced for the second time at $400^{\circ} \mathrm{C}$. This experiment therefore shows that the highest reduction temperature to which the sample previously has been subjected determines the peak position of the $\mathrm{CO}$ absorption band. Reduction at $200^{\circ} \mathrm{C}$ for $30 \mathrm{~min}$ is already sufficient to reduce the copper oxide crystallites completely. 


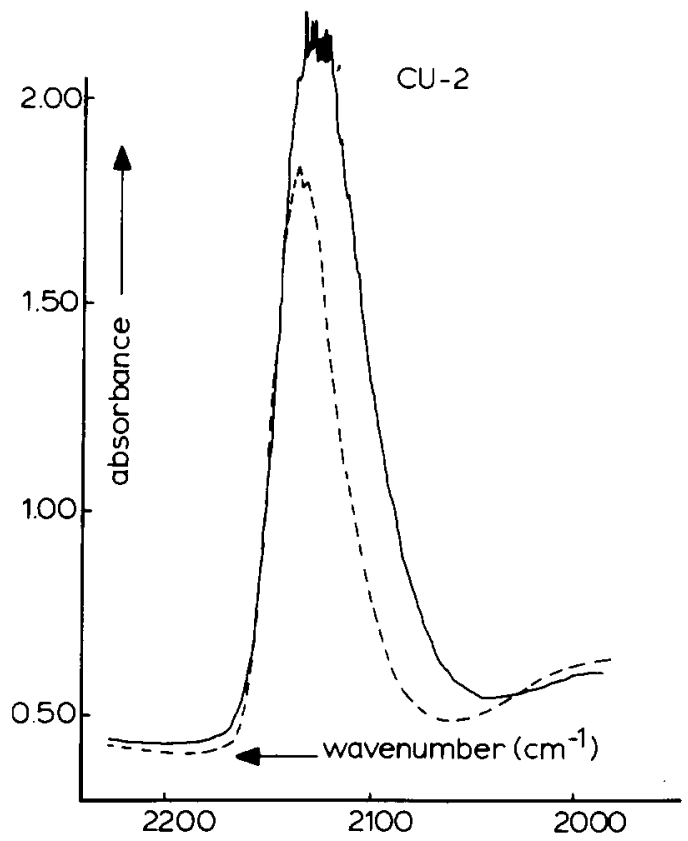

Fig. 2. Infrared spectra of $\mathrm{CO}$ adsorbed on $\mathrm{Cu} / \mathrm{SiO}_{2}$, sample $\mathrm{CU}-2$. After reduction during $15 \mathrm{~h}$ at $200^{\circ} \mathrm{C} \mathrm{( \longrightarrow )} \mathrm{and} 300^{\circ} \mathrm{C}(---)$.

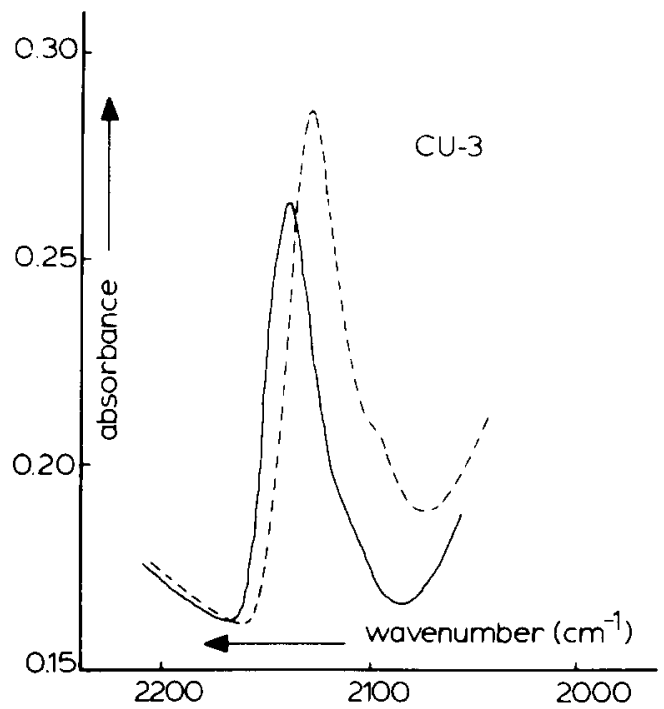

Fig. 3. Infrared spectra of $\mathrm{CO}$ adsorbed on $\mathrm{Cu} / \mathrm{SiO}_{2}$, sample $\mathrm{CU}-3$. After reduction during $15 \mathrm{~h}$ at $300^{\circ} \mathrm{C} \mathrm{( \longrightarrow )} \mathrm{and} 400^{\circ} \mathrm{C}(---)$. 
Table 2

Influence of the reduction temperature and time of CU-3 on the infrared absorption band of adsorbed $\mathrm{CO}$. The catalyst was oxidized between reduction 2 and 3 only

\begin{tabular}{llll}
\hline Reduction & $\begin{array}{l}\text { Temperature } \\
\left({ }^{\circ} \mathrm{C}\right)\end{array}$ & $\begin{array}{l}\text { Time } \\
\text { (hours) }\end{array}$ & $\begin{array}{l}\text { Peak maximum } \\
\left(\mathrm{cm}^{-1}\right)\end{array}$ \\
\hline 1 & 300 & 20 & 2139 \\
2 & 400 & 15 & 2129 \\
3 & 200 & 0.5 & 2129 \\
\hline
\end{tabular}

When the copper particles have been prolongedly treated in hydrogen at high temperatures, they display infrared spectra of adsorbed $\mathrm{CO}$ that are closely related. This is apparent from fig. 4 , in which the spectra for the severely reduced catalysts have been collected. The spectra for the deposition-precipitated samples CU-1 and CU-2 are equal when we ignore the differences in intensity, which are due to the different optical density of the discs and the different specific copper surface area of the catalysts. The impregnated catalyst CU-3 gives rise to a band at lower wavenumbers with a shoulder around $2100 \mathrm{~cm}^{-1}$. This leads us to the conclusion that for comparing copper catalysts by their infrared spectra of adsorbed $\mathrm{CO}$, the shift of the absorption band upon more severe reduction is at least as important as is the result after prolonged reduction.

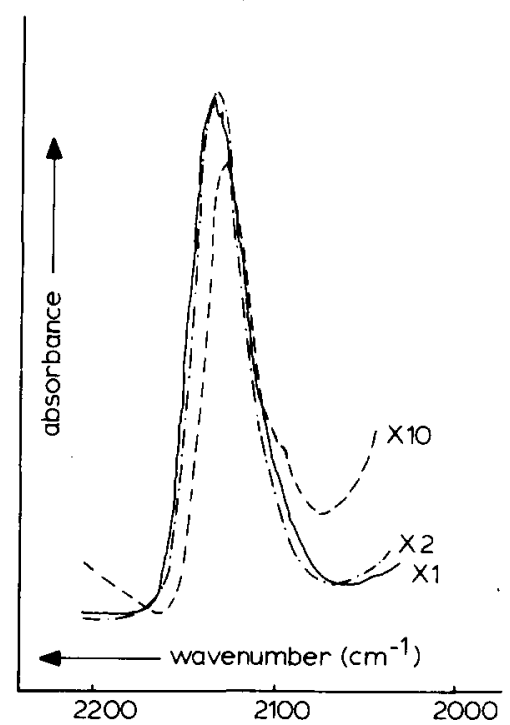

Fig. 4. Infrared spectra of $\mathrm{CO}$ adsorbed on $\mathrm{Cu} / \mathrm{SiO}_{2}$ after prolonged reduction at high temperature; sample $\mathrm{CU}-1(-.-$.$) , \mathrm{CU}-2(-)$ and $\mathrm{CU}-3(--)$. 


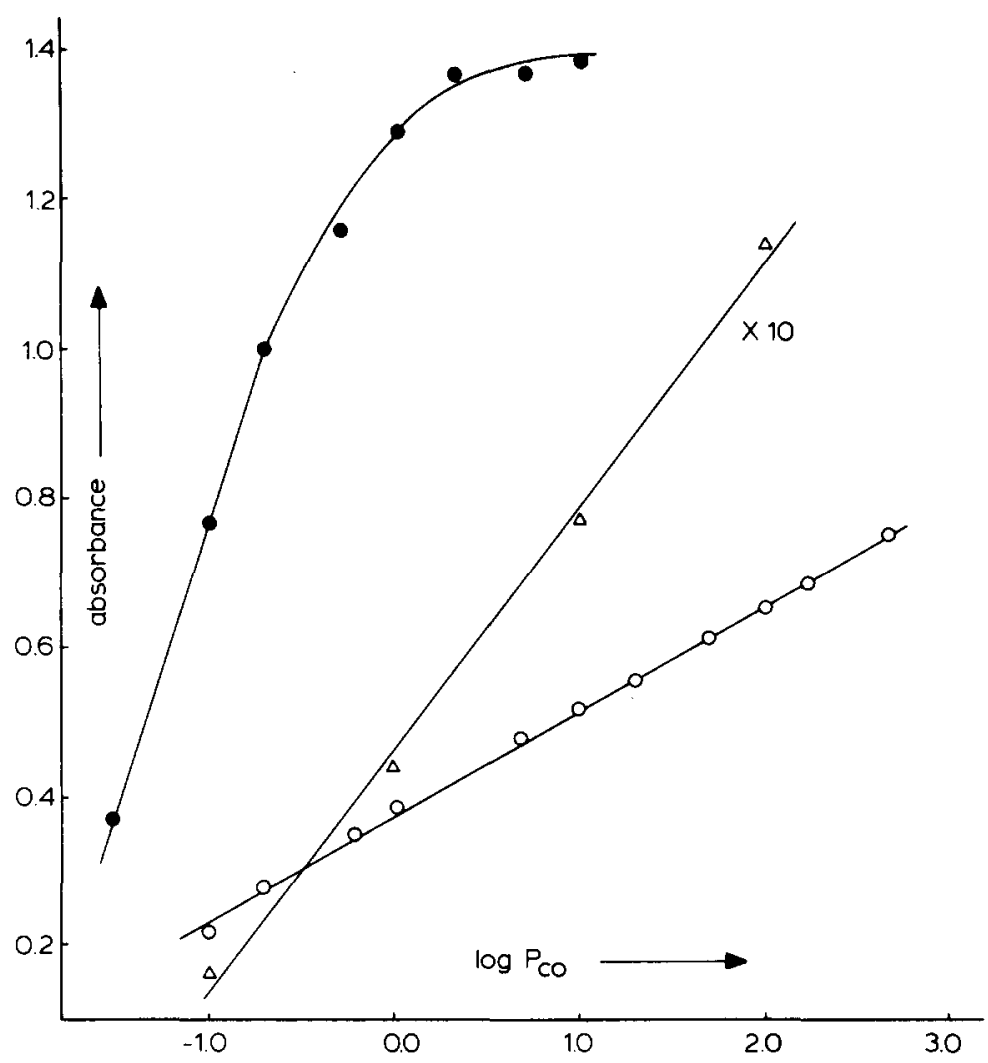

Fig. 5. The peak height of the absorption band of $\mathrm{CO}$ adsorbed on $\mathrm{Cu} / \mathrm{SiO}_{2}$ as a function of CO pressure; sample CU-1 (०), CU-2 $(\bullet)$ and CU-3 $(\Delta)$.

For all catalysts the absorbance at the peak maximum was measured as a function of the CO-pressure. The results have been collected in fig. 5. For catalysts CU-1 and CU-3 a linear relationship between the absorbance and the logarithm of the CO pressure exists. For CU-2 the band intensity seems to saturate at high pressures, but the large values of the absorbance causes the data to be less reliable.

A remark should finally be made about the importance of the vacuum conditions during these experiments. The spectra in fig. 6 have both been recorded after reduction of catalyst CU -3 at $300^{\circ} \mathrm{C}$ for $15 \mathrm{~h}$. The more intense band at lower frequency was found after a leakage for a few minutes while pumping off the hydrogen at high temperature. Subsequent exposure to oxygen had hardly an effect on the absorption band which shows that the surface was already completely covered with oxygen. 


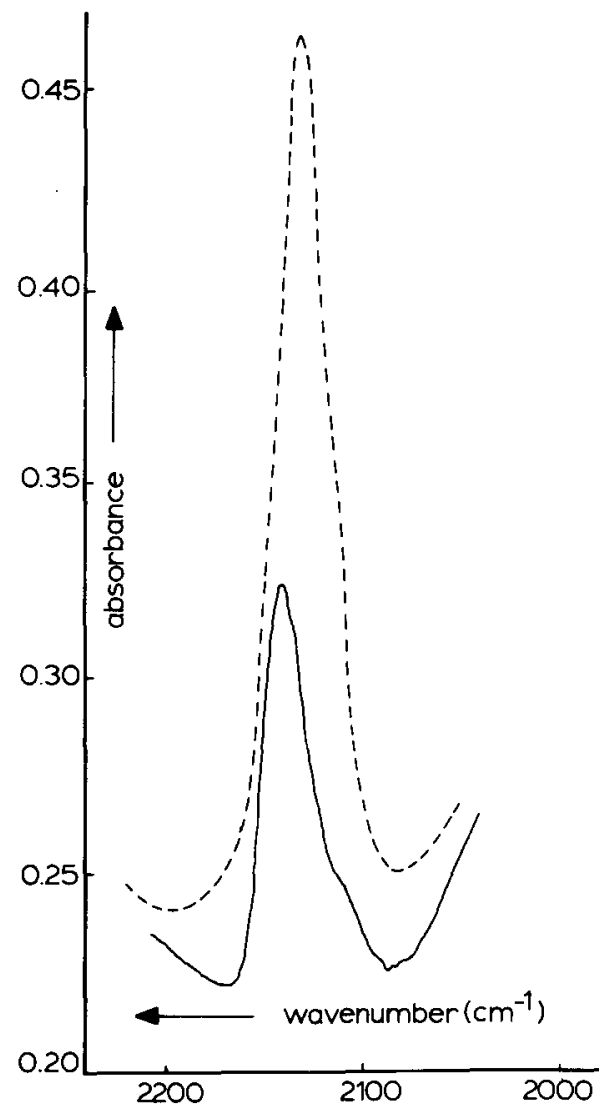

Fig. 6. Infrared spectra of $\mathrm{CO}$ adsorbed on sample CU-3 after reduction at $300^{\circ} \mathrm{C}$ and subsequent evacuation with (---) and without (-) a leakage.

\subsection{Electron micrographs}

Above we showed that the effect of the pretreatment of the catalysts on the infrared spectra of section 3.1 cannot be attributed to the degree of reduction of the copper species. We therefore investigated the catalysts in the transmission electron microscope. In figs. 7 and 8 electron micrographs are represented that have been selected from a large number of bright and dark field micrographs that provided consistent results. The catalysts prepared by deposition-precipitation (CU-1 and CU-2) show a very homogeneous distribution of copper particles over the carrier with a fairly narrow size-distribution. With CU-1 a small number of rather large particles (about $120 \AA$ diameter) besides many particles that are smaller (about $60 \AA$ ) can be seen. Catalyst CU-2 shows the same bimodal particle-size distribution, but now the 

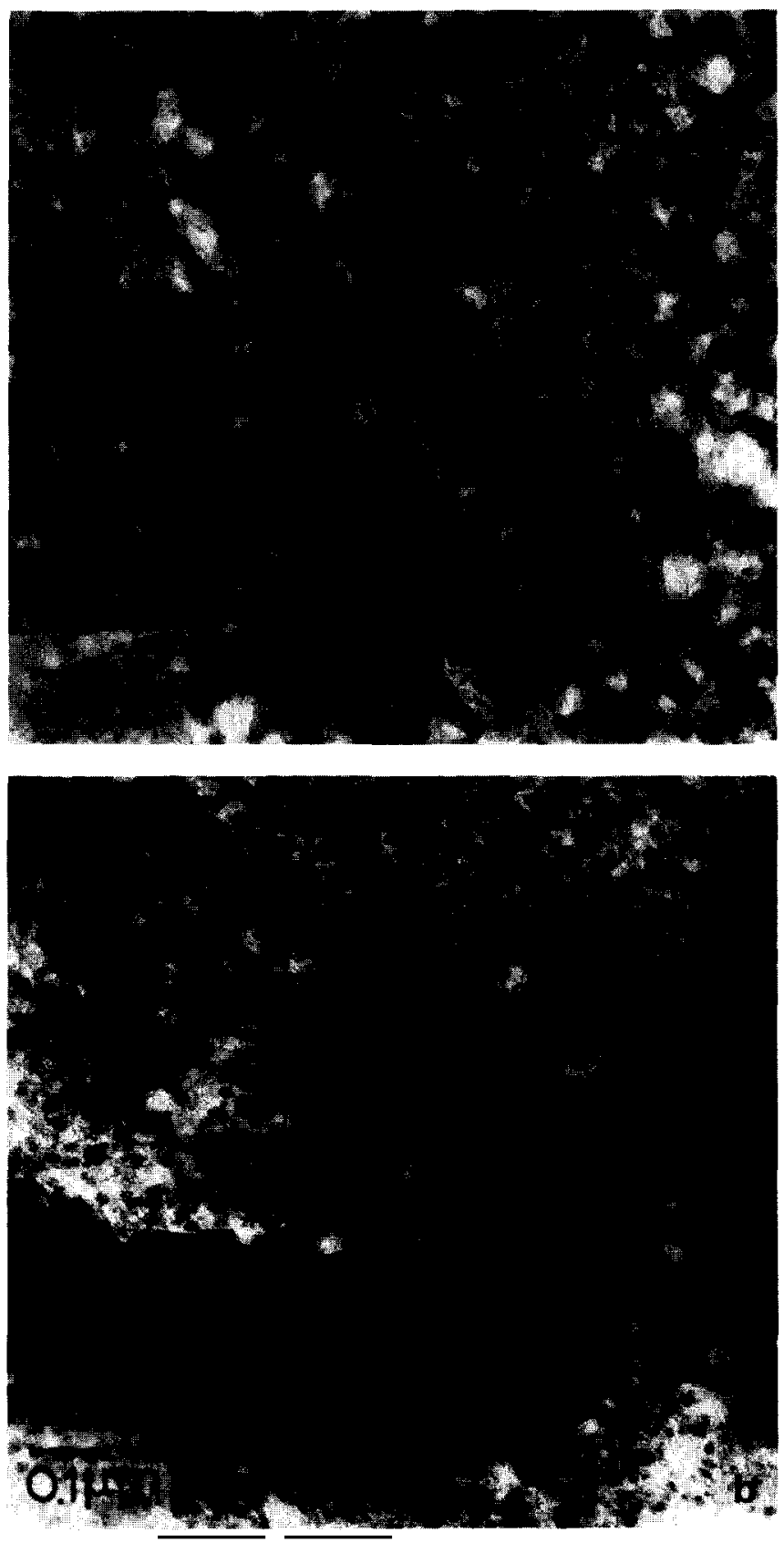

Fig. 7. Electron micrographs of $\mathrm{Cu} / \mathrm{SiO}_{2}$ catalysts, reduced at $300^{\circ} \mathrm{C}$. (a) Catalyst $\mathrm{CU}-1$, (b) catalyst CU-2. 


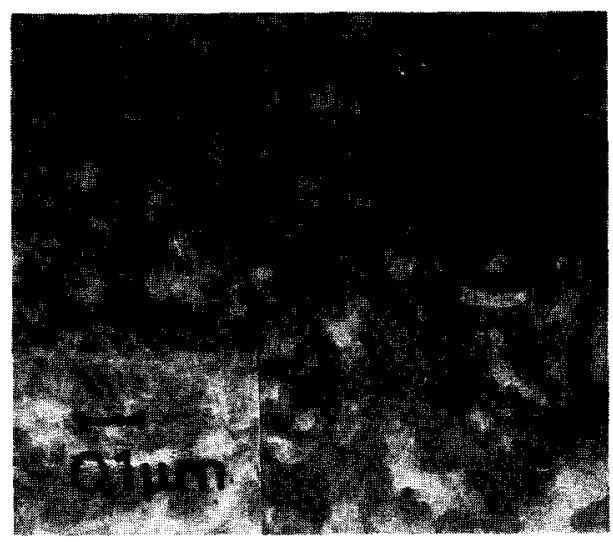

Fig. 8. Electron micrograph of catalyst CU-3, reduced at $300^{\circ} \mathrm{C}$.

larger particles are more numerous. This is reflected in the (volume-) average diameter from X-ray line broadening of 110 and $190 \AA$ for CU-1 and CU-2, respectively. The impregnation catalyst CU-3 has a very broad particle-size distribution, ranging from 40 to $5000 \AA$. We think that the dispersion of the metal by impregnation depends strongly on the drying procedure. Comparing results from different investigators for impregnation catalysts is therefore hardly possible. With our CU-3 there are still a large number of small particles (about $100 \AA$ ) which contribute appreciably to the total copper surface, but it is possible that other investigators have had mainly particles of $200 \AA$ and larger.

\section{Discussion}

Using single crystals, vapour-deposited films and supported $\mathrm{Cu}$-particles Pritchard and co-workers [2] investigated the adsorption of carbon monoxide on $\mathrm{Cu}$-surfaces most profoundly. As a support they used $\mathrm{SiO}_{2}, \mathrm{Al}_{2} \mathrm{O}_{3}$ and $\mathrm{MgO}$. Sheppard and Nguyen [5] have published an excellent survey of infrared studies on adsorbed species dealing also with adsorption of $\mathrm{CO}$ on $\mathrm{Cu}$.

With the closely packed (111) and (100) copper surfaces Pritchard et al. [2] recorded band maxima at 2070 to $2090 \mathrm{~cm}^{-1}$ on adsorption of $\mathrm{CO}$ at $77 \mathrm{~K}$. The stepped (211), (311) and (755) surfaces showed a main maximum at 2100 to 2110 $\mathrm{cm}^{-1}$. Especially the spectra of the (211) and (755) surfaces are important. These surfaces contain terraces having (111)-structure separated by (100)-like steps. The width of the (111) terraces on the (755) surface is larger than that on the (211) surface. In spite of the presence of (111) planes adsorption of $\mathrm{CO}$ on the (211) and (755) surface does not lead to frequencies characteristic of the flat (111) surface 
(2070 to $2076 \mathrm{~cm}^{-1}$ ). On the (111) and (100) surface CO is adsorbed in ordered structures as apparent from LEED experiments [6,7]. Since $\mathrm{CO}$ adsorbed in these structures shows frequencies from 2070 to $2076 \mathrm{~cm}^{-1}$ with the (111) surface, we feel that the structure of the adsorbed layer on extended (111) planes cannot be established on the relatively small terraces on the (211) and (755) surfaces. There is a density of steps on these surfaces that prevents adsorption of $\mathrm{CO}$ in an ordered structure exhibiting frequencies of 2070 to $2090 \mathrm{~cm}^{-1}$.

Using $\mathrm{Cu}$ films deposited on to glass or alumina Pritchard et al. observed adsorbed $\mathrm{CO}$ to display frequencies of $(2104 \pm 2) \mathrm{cm}^{-1}$. Impregnated $\mathrm{Cu} / \mathrm{SiO}$ and $\mathrm{Cu} / \mathrm{Al}_{2} \mathrm{O}_{3}$ catalysts reduced at $250^{\circ} \mathrm{C}$ or $350^{\circ} \mathrm{C}$ showed frequencies of $(2105 \pm 3) \mathrm{cm}^{-1}$, while alumina-supported catalysts containing more than $5 \% \mathrm{Cu}$ showed frequencies from 2110 to $2120 \mathrm{~cm}^{-1}$. The results with single-crystal surfaces suggest that both vapour-deposited $\mathrm{Cu}$-films and supported $\mathrm{Cu}$-particles mainly expose stepped surfaces. We cannot indicate precisely the critical step density where domains of adsorbed CO characteristic of the (111) or (100) surface cannot be markedly established. The step density of the films and supported catalysts is therefore not accurately known. Apparently $\mathrm{Cu}$-crystallites present both in films and in supported catalysts interact differently with magnesia. Owing to the interaction $\mathrm{Cu}$-crystallites on magnesia expose more extended closely packed planes. As a result $\mathrm{CO}$ adsorbed on $\mathrm{Cu} / \mathrm{MgO}$ shows frequencies between 2079 and $2085 \mathrm{~cm}^{-1}$.

Seanor and Armberg [8] recorded frequencies appreciably higher than 2110 $\mathrm{cm}^{-1}$ with silica-supported copper. They observed a frequency of $2143 \mathrm{~cm}^{-1}$, which gradually decreased to $2130 \mathrm{~cm}^{-1}$ at an increasing number of reduction and degassing treatments at $400^{\circ} \mathrm{C}$. With $\mathrm{Cu} / \mathrm{SiO}_{2}$ and $\mathrm{Cu} / \mathrm{Al}_{2} \mathrm{O}_{3}$ Pritchard et al. also found a decrease in frequency from $(2122 \pm 2) \mathrm{cm}^{-1}$ to $(2105 \pm 3) \mathrm{cm}^{-1}$, when the reduction temperature was raised from $140^{\circ} \mathrm{C}$ to $350^{\circ} \mathrm{C}$. Admission of oxygen led to higher frequencies, which decreased again after reduction. Pritchard et al. therefore attributed bands at higher frequencies than about $2110 \mathrm{~cm}^{-1}$ to the presence of not completely reduced copper. $\mathrm{CO}$ adsorbed on $\mathrm{CuO}$ shows frequencies of about $2135 \mathrm{~cm}^{-1}[8,9]$.

Wavenumbers above $2104 \mathrm{~cm}^{-1}$ recorded in this work cannot be due to incompletely reduced copper. The data of table 2 demonstrate that reduction for $30 \mathrm{~min}$ at $200^{\circ} \mathrm{C}$ is sufficient to reduce the copper oxide in CU-3 completely. The most convincing evidence is from the deposition-precipitated catalysts, where more severe or more prolonged reduction shifted the frequencies to higher values. This was most pronounced with CU-1. After the first reduction $\left(15 \mathrm{~h}\right.$ at $\left.300^{\circ} \mathrm{C}\right)$ the frequency peaked at $2104 \mathrm{~cm}^{-1}$, which agrees with values published for films and severely reduced catalysts by [2]. Increase of the reduction time or temperature raised the frequency of the maximum to $(2135 \pm 4) \mathrm{cm}^{-1}$.

Since we measured a maximum above $2130 \mathrm{~cm}^{-1}$ with fully reduced supported copper catalysts, there must be still another structure of metallic copper surfaces. The structure must differ from that of flat closely packed or stepped surfaces. In the establishment of the structure of $\mathrm{Cu}$-surfaces exhibiting frequencies above 2120 
$\mathrm{cm}^{-1}$ we were guided by results published by Moskovits and Hulse [10,11]. These authors investigated copper-carbonyl complexes isolated in an argon matrix. With larger clusters of $\mathrm{Cu}$-atoms they measured frequencies agreeing with those observed with films and stepped surfaces provided a red shift of approximately $15 \mathrm{~cm}^{-1}$ was taken into account. The red shift is commonly encountered in infrared spectra of argon-isolated species. The wavenumbers observed by Moskovits and Hulse corrected for the red shift are 2143,2131 and $2127 \mathrm{~cm}^{-1}$. Their results indicate that species in which $\mathrm{CO}$ is bonded to an isolated $\mathrm{Cu}$-atom or to a $\mathrm{Cu}$-atom strongly interacting with only a small number of other $\mathrm{Cu}$-atoms are displaying frequencies above 2120 $\mathrm{cm}^{-1}$.

The small anisotropy of the surface energy of copper $[3,4]$ causes the equilibrium shape of $\mathrm{Cu}$-crystallites to be rather spherical. Small equilibrated $\mathrm{Cu}$-particles will therefore not contain straight steps of a considerable length in their surface, but curved steps only. The curved steps will consist of short straight rows of atoms containing a small number of $\mathrm{Cu}$-atoms even down to two or one. Besides bonding of $\mathrm{CO}$ to protruding single $\mathrm{Cu}$-atoms as a species similar to $\mathrm{Cu}-\mathrm{CO}$, bonding to the end of a step similar to $\mathrm{Cu}-\mathrm{Cu}-\mathrm{CO}$ or to both ends of very small rows similar to $\mathrm{OC}-\mathrm{Cu}-\mathrm{Cu}-\mathrm{CO}$ can be expected with small equilibrated $\mathrm{Cu}$-particles. To explain our infrared results we thus assume that small $\mathrm{Cu}$-crystallites can expose surfaces having many protruding $\mathrm{Cu}$-atoms or small clusters of $\mathrm{Cu}$-atoms.

We next have to explain how the $\mathrm{Cu}$-particles in our catalysts can expose both straightly stepped and atomically rough surfaces depending on the thermal treatment. Electron micrographs showed the impregnated catalyst CU-3 to contain well dispersed, very small, as well as strongly clustered copper nitrate particles. Since the amount of copper (II) ions atomically dispersed on the silica surface was small, the copper oxide was reduced fast. The completely reduced crystallites have therefore been rather prolonged at an elevated temperature during the first reduction $(20 \mathrm{~h})$ at $300^{\circ} \mathrm{C}$. The very small copper crystallites resulting from the reduction of rather symmetrical copper oxide could therefore take up their equilibrium shape. The clustered larger copper crystallites ask for a considerable longer period to assume their equilibrium shape. The driving force for coalescence to large symmetrical crystallites, which is due to the local curvature of the surface is rather small, which causes the rate at which the equilibrium shape is taken up to be small. After the first reduction both the very small crystallites and the coalescing clusters of crystallites will consequently have atomically rough surfaces. As a result the completely reduced, impregnated catalyst CU-3 showed a band with a maximum at $2139 \mathrm{~cm}^{-1}$. When the catalyst was reduced for $15 \mathrm{~h}$ at $400^{\circ} \mathrm{C}$, the extent of reduction was not raised, but the clusters of $\mathrm{Cu}$-crystallites coalesced to large single crystallites (up to about $5000 \AA$ ). Though the atomically rough surfaces of the small crystallites (100 $\pm 40 \AA$ ) were still dominating the spectrum, the stepped surfaces of the large particles exposed also a marked surface area. By calculations on assumed bimodal particle-size distributions we assessed the surface area of a limited fraction of large crystallites to be appreciable. The marked surface area of a small curvature leads to the 
well resolved shoulder shown in fig. 3 at about $2100 \mathrm{~cm}^{-1}$, which is characteristic of more extended stepped surfaces. A slight sintering of the small particles shifted the maximum of the main peak to $2129 \mathrm{~cm}^{-1}$.

As we have demonstrated experimentally [9], a large fraction of the copper ions in the catalyst CU-1 had reacted with the silica support. On reduction of the fresh catalyst the copper oxide species deposited onto the silica, the copper ions of which have not reacted with the silica, rapidly reacts to small copper crystallites. The small copper crystallites subsequently capture copper atoms migrating over the silica surface. The migrating copper atoms are resulting from the reduction of copper ions atomically dispersed in the silica, which reduction was shown experimentally to proceed appreciably more slowly than that of the other copper oxide species. This brings about the copper crystallites to grow mainly parallel to the surface of the support. As a result flat, rather extended crystallites are obtained. The extended stepped top surface of these crystallites exhibits an absorption band peaked at 2104 $\mathrm{cm}^{-1}$. Oxidation and reduction change the kinetically established flat crystallites in to the more spherical crystallites of the thermodynamic equilibrium. Accordingly the frequency of the maximum shifts to $2131 \mathrm{~cm}^{-1}$. The extended flat crystallites resemble the mono atomic rafts described by Prestridge et al. [12]. The thickness of our flat copper crystallites is of the order of that of the copper particles rapidly developed from the copper oxide species present on the silica surface. The small interaction of metallic copper atoms and the silica causes the copper particles to tend towards a spherical shape. As a result the thickness of our flat extended particles will be more than that of one or two copper atoms. After the first reduction of catalyst CU-1, the maximum of the absorption band is at $2104 \mathrm{~cm}^{-1}$, which points to the presence of stepped surfaces of a low curvature. Fig. 1 shows also a marked intensity at $2070-2090 \mathrm{~cm}^{-1}$ after the first reduction, which indicates more extended flat surfaces without steps to be also markedly present. The flat particles presumably have a larger copper surface area than the thermodynamically more stable crystallites present after oxidation and reduction. Provided the molecular intensity is not appreciably different, the drop in absorption from 1.03 to 0.52 (table 2) is due to the change in shape of the particles. With subsequent oxidation and reduction the about spherical copper particles are re-established.

With catalyst CU-2, which has a higher copper load, more copper species had been deposited onto the support. Owing to this the height of the copper crystallites resulting from the more easily reducible material is larger. Addition of copper atoms from the surface of the support to the larger crystallites leads to particles of a more hemispherical shape than with the freshly reduced catalyst CU-1. The resulting larger curvature of the surface causes the maximum of the absorption band to be situated at $2130 \mathrm{~cm}^{-1}$. However, the marked absorption at $2100 \mathrm{~cm}^{-1}$ (fig. 2) indicates that extended flat crystallites were also present after the first reduction. Subsequent oxidation-reduction cycles shift the maximum to a slightly higher frequency (2136 $\mathrm{cm}^{-1}$ ), while the intensity at $2100 \mathrm{~cm}^{-1}$ was appreciably reduced.

The catalysts CU-1 and CU-2 contain particles of a mean size of 60 and $120 \AA$, 
respectively. Since both catalysts display absorption maxima at about the same frequency after equilibration, the particle size has not a very large effect. This is in keeping with the low anisotropy of the surface energy of copper.

The data published on $\mathrm{Cu} / \mathrm{SiO}_{2}$ catalysts show much diversity. We feel that this is due to the strong effect of the impregnation procedure and of details of the thermal pretreatment on the shape of the copper crystallites. Our results can be used to rationalize the data of the literature. The shift from 2120 to $2105 \mathrm{~cm}^{-1}$ on raising the reduction temperature from 140 to $250^{\circ} \mathrm{C}$, found by Pritchard et al., may be due to formation of flat extended Cu-crystallites. Since the catalysts were not completely re-oxidized and again reduced, recrystallization to more spherical particles could not proceed. Since the reduction of copper oxide at $140^{\circ} \mathrm{C}$ is slow, the above shift may be due to the presence of remaining copper oxide, which adsorbs $\mathrm{CO}$ displaying a maximum at about $2135 \mathrm{~cm}^{-1}$. The use of $\mathrm{MgO}$ as a support presumably leads to particles approaching the structure of rafts with a flat surface at the top. Seanor and Amberg reduced their $\mathrm{Cu} / \mathrm{SiO}_{2}$ longer at a more elevated temperature $\left(400^{\circ} \mathrm{C}\right)$. Their $\mathrm{Cu}$-particles could take up the equilibrium shape. Coalescence of clusters gradually shifted the maximum to lower frequencies.

In conclusion we can say that the vibrational frequency of carbon monoxide adsorbed on copper is a function of the surface roughness. The surface roughness depends upon the supply of copper atoms towards the particles during reduction on the one, and the particle size on the other hand. The diversity of data of infrared studies of $\mathrm{CO}$ adsorption on impregnated copper catalysts is caused by the irreproducible preparation and pretreatment of these catalysts. The differences are caused by large changes in particle shape and particle size distribution, and to a smaller extent to differences in the degree of reduction.

\section{References}

[1] R. van Hardeveld and F. Hartog, Adv. Catal. 22 (1975) 75.

[2] J. Pritchard, T. Catterick and R.K. Gupta, Surface Sci. 53 (1975) 1.

[3] B.E. Sundquist, Acta Met. 12 (1964) 67.

[4] M. McLean, Acta Met. 19 (1971) 387.

[5] N. Sheppard and T.T. Nguyen, Advances in Infrared and Raman Spectroscopy, eds. R.J.H. Clark and R.E. Hester, Vol. 5 (Heyden, London, 1978) chapter 2.

[6] J. Pritchard, J. Vacuum Sci. Technol. 9 (1972) 895.

[7] K. Horn and J. Pritchard, Surface Sci. 55 (1976) 701.

[8] D.A. Seanor and C.H. Amberg, J. Phys. Chem. 4? (1965) 2967.

[9] K.P. de Jong, J.W. Geus and J. Joziasse, J. Catalysis 65 (1980) 437.

[10] M. Moskovits and J.E. Hulse, Surface Sci. 61 (1976) 302.

[11] M. Moskovits and J.E. Hulse, J. Phys. Chem. 81 (1977) 2004.

[12] E.B. Prestridge, G.H. Via and J.H. Sinfelt, J. Catalysis 50 (1977) 115. 